\title{
A REVIEW ON CITIZEN SCIENCE (CITSCI) APPLICATIONS FOR DISASTER MANAGEMENT
}

\author{
Sultan Kocaman ${ }^{1, *}$, Berk Anbaroglu ${ }^{1}$, Candan Gokceoglu ${ }^{2}$, Orhan Altan ${ }^{3}$ \\ ${ }^{1}$ Hacettepe Uni., Dept. of Geomatics Eng. 06800 Beytepe Ankara, Turkey \\ $<$ sultankocaman><banbar>@ hacettepe.edu.tr
}

${ }^{2}$ Hacettepe Uni., Dept. of Geological Eng. 06800 Beytepe Ankara, Turkey - cgokce@ hacettepe.edu.tr

${ }^{3}$ Istanbul Technical University, Department of Geomatics Engineering, Istanbul, Turkey - oaltan@itu.edu.tr

KEY WORDS: Citizen Science, CitSci, VGI, Disaster Management, Sustainability, Open Data

\begin{abstract}
:
The traditional way of doing science has been changing with the recent movements on open science, open data and the world-wide spread of volunteer activities. With the help of technological advancements, in particular mobile technologies, do-it-yourself kits and free online education sources, ordinary citizens may contribute to scientific processes based on their interest and abilities. Citizen Science (CitSci) is an active research agenda which draws the interest of scientists from different disciplines. It investigates the various contributions that citizens could do to improve scientific process. These contributions are utilized in diverse areas ranging from biology to environmental monitoring to classification of galaxies, all of which have a spatiotemporal dimension. The emerging developments in spatial information science allow the public to understand their environment better and efficiently. In this way society would have the means to deal with complex modern problems including but not limited to water/air pollution monitoring and mapping a region after a natural disaster to aid relief and recovery efforts. In addition, there is a growing public demand for research projects involving CitSci; because such collaborative efforts can be critical to achieve sustainability goals. The aim of this paper is to provide an overview on the state-of-the art methods and applications where CitSci is a crucial component in different phases of disaster management, from environmental protection to risk analysis and aid provision. Use of CitSci methods in disaster situations can be vital for different reasons, such as acquisition of local and most current information, organization of help during emergency, development of instant rescue plans, accurate information dissemination, and monitoring of the post-disaster influences to the society and the environment. Open issues on the use of CitSci methods in disaster management, such as data quality, technical and management-related barriers, open-standards and interoperability, and volunteer engagement, will also be discussed.
\end{abstract}

\section{INTRODUCTION}

The number of extreme events has been increasing with the climate change and the rise of human population. In addition, almost all events are nowadays being recorded with the help of the developments in information and communication technologies. According to the records, the number and severity of disasters have been increasing from 1980s to today (Figure 1). In their study, Cutter et al. (2015) stated that the annual global economic losses from geophysical, hydro-meteorological and climatological events could double from 2005 levels to 2030 and exceed US\$300 billion. Climate change, globalization, technological change, urbanization and political and economic instability risk more lives and assets (Cutter et al., 2015).

For sustainable societies, improved disaster-risk management and resilience is essential and an important focus both at local and global level. United Nations (UN) adopted 17 Goals, also known as 2030 goals, on September 25th 2015 at the Summit to end poverty, protect the planet and ensure prosperity for all as part of a new sustainable development agenda (UN Sustainable Development Goals, 2018). Each goal has specific targets to be achieved until the year 2030. With these new goals, all countries will mobilize efforts to end all forms of poverty, fight inequalities and tackle climate change, while ensuring that no one is left behind.

Citizen Science (CitSci), work undertaken by civic educators together with citizen communities to advance science, foster a broad scientific mentality. This encourages democratic engagement, which allows societies to deal with complex modern

*Corresponding author

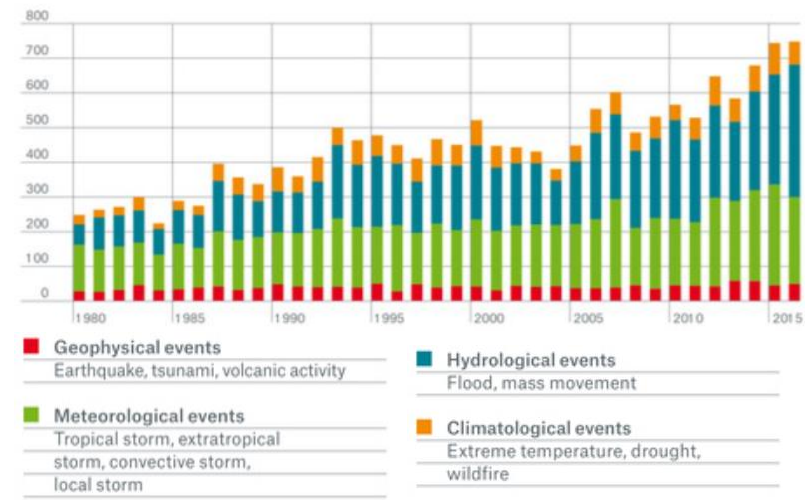

Figure 1. Number of events in years (Munich RE, 2017).

problems. There is a growing public demand for research projects involving CitSci (Silvertown, 2009); because such collaborative efforts, which require solid technological infrastructure, can be critical to achieve the aims of especially ecology-related research projects and also to achieve the sustainability goals. The number of CitSci projects running in the domains of environmental monitoring, wildlife monitoring, education, urban data collection, etc. has increased rapidly during the last decades. These projects especially serve to the 2030 Goals, specifically the Quality Education, Clean Water and Sanitation, Sustainable Cities and Communities, Climate Action, Life Below Water and Life on Land. The trends in open science, open data and the changes in government policies and laws towards supporting open government data in many countries can help to increase public awareness in CitSci projects and achieve 2030 Goals. 
Geospatial technologies have a crucial role towards addressing the 2030 goals, especially in terms of citizen participation. Goodchild (2007) has coined the term Volunteer Geographical Information (VGI). With this, citizens are not only consumers of maps but also producers. In this way, humans are considered as sensors. The network of human sensors has over 6 billion components, each an intelligent synthesizer and interpreter of local information and VGI as an effective use of this network, enabled by Web 2.0 and the technology of broadband communication (Goodchild, 2007). Disaster management is also an important area in which VGI has value to offer (Haworth and Bruce, 2015).

Haklay (2013) described the ladder of participation to CitSci projects in four levels (Figure 2). Although other typologies of CitSci are offered (e.g. Cooper et al., 2007; Wilderman, 2007; Bonney et al., 2009; Wiggins and Crowston, 2011), where classifications of different aspects such as the level of informal science education, the involvement of participants in various aspects of research or the purpose of the project, the generic typology of Haklay (2013) can be customized based on the disaster type (e.g. landslides, infectious diseases, etc.).

\begin{tabular}{l}
\hline Level 4 'Extreme Citizen Science' \\
• Collaborative science - problem definition, data collection and analysis \\
\hline Level 3 'Participatory science' \\
- Participation in problem definition and data collection \\
\hline Level 2 'Distributed Intelligence' \\
- Citizens as basic interpreters \\
- Volunteered thinking \\
\hline Level 1 'Crowdsourcing' \\
• Citizens as sensors \\
- Volunteered computing
\end{tabular}

Figure 2. Levels of participation and engagement in CitSci projects (Haklay, 2013).

The main aim of this paper is to discuss the possibilities and opportunities which CitSci can bring to disaster management. A literature survey on the CitSci projects in disaster management is performed for pre- and post-disaster stages. In the pre-disaster stage, environmental monitoring and protection, risk assessment and planning are considered. The post-disaster stage involves the emergency plans and activities, provision of public participation, and the assessment of the long term effects. Open issues in many disaster-related CitSci projects are provided in Section 3. The same section also includes the role of open data and the recent developments in open government data, as the data collected by the governments are most reliable in many aspects and plays a crucial role in CitSci projects. The conclusions summarize the gaps observed in the field and the proposals for the future.

\section{ROLE OF CITIZEN SCIENCE IN DISASTER MANAGEMENT}

\subsection{Potential Application Areas of CitSci for Disaster Management}

Categories and potential indicators to climate change and impacts and responses are summarized in the National Climate Assessment Report (2011). The indicator summary given in report (Table 1, pages 20-21) can form a good basis where CitSci methods can be used for rapid and effective data collection, and even the analysis. The indicators are categorized as following:
- Health \& Safety: Weather-related mortality (e.g., heat, floods, and wind), air quality, infectious disease risk/geographic extent (e.g., malaria; potential and actual), number of people experiencing heat waves multiplied by the number of days, weather related illness, chronic health conditions (e.g., asthma), health in vulnerable populations, healthcare access are all indicators of health and safety.

- Population Dynamics: Human well-being (composite indicator - sense of place; stability, the sensation of living in a risky environment health; cost of living; community habitability; effects on recreational opportunities; how much time spent outside), vulnerability (populations, regions; exposure, sensitivity, and adaptability; socioeconomic vulnerability; population sensitivity; elderly and family structure), settlement and movement (displacement, migration, location of populations; population density; population change; population distribution; e.g.), natural amenities scale, which includes climate, topography, and access to water to understand depopulation in rural communities), social network mapping, persons in 100- and 500-year floodplains and coastal storm surge zones, "special needs" populations in those zones, Social capital, connectivity and networks (includes population learning/literacy/attitudes; knowledge, action, and practice), societal awareness of climate change (understanding; communication; education; attitudes; climate literacy), behavioral shifts in transportation (alternative transportation; e.g., indicator by Department of Transportation about how long we sit in traffic and congestion patterns, which lends to greenhouse gas emissions and affects quality of life), social disruption (e.g., communities affected by hurricanes; long-term consequences), etc.

- Equity \& Justice: Socioeconomic inequalities (spatial/place-based; who can move; social networks; access to services, infrastructure, institutions; middle class crunch; ability to cope post-disaster), environmental justice (exposure, vulnerability, resiliency; subsistence practices; housing; e.g., subsistence practices that are being modified, impacts on livelihoods), etc.

- Community Capacity: Such as risk, stress, community habitability (displacement of entire populations from an area), response capacity (potential vs. action), what is actually being done for mitigation and adaptation (e.g., money spent on flood proofing and other hazard mitigation spending), transformational adaptation (anticipatory), etc.

- Cultural Impacts: Such as aesthetic environment (e.g., color lost in leaves in Smoky Mountains), cultural richness of communities, impacts on cultural practices, cultural processes, cultural icons (e.g., maple tree), cultural identity, human social systems, ways of life, etc.

- Economy: Such as climate investment (resiliency, adaptation and mitigation), risk of investments, economic assets at risk, direct/indirect economic loss/gains (e.g., increased production in warmer/wetter areas), infrastructure, lives, climate risk reduction and costs (costbenefit), economic diversity, tourism, agriculture, forestry, employment/unemployment (in certain fields), energy, insurance (e.g., property losses from extreme weather events), change in when people work (e.g., as a result of temperature, heat index, precipitation, power outages), lost work productivity, etc. 
- Institutions /Governance: Such as institutional (learning) capacity flexibility and adaptive management (how flexible is infrastructure and institutions), institutional coordination - governance and leadership, government structure, changes in governance, civil society, tax base, costs/responsibilities, emergency medical technicians/healthcare workers, emergency preparedness plans, early warning systems, effectiveness of communications (e.g., early warning systems), index focused on knowledge systems and innovation (ways to monitor progress, advancement, conditions, for innovation), preparedness, response capacity (potential vs. action), insurance and reinsurance, intergovernmental issues, what is actually being done for mitigation and adaptation, confidence/attitudes about government (sense of security and confidence in government), rate of emissions and what trajectory it puts us on for long-term, etc.

- $\quad$ National Security: Such as security and confidence, water security, food security, energy security, housing security, resource conflict, etc.

- Thresholds / Tipping points: Such as extreme events (probabilities; number of 100-year or "greater" events), climate change added to other stressors (e.g., storms in coastal areas combined with sea-level rise), etc.
- $\quad$ Physical / Natural: Such as heat (air quality; ozone and particulate matter), precipitation, urban heat island, land cover and change, human feedbacks on local and regional climate, weather extremes (catastrophic; mortality rates), location/duration/timing/severity of precipitation, drought, flood, agriculture (food security; livestock and crop disease; fisheries/forests), ecological feedback loops (unexpected /surprises), coasts, vegetation migration, biological diversity, ecological health, wildland/urban interface issues (e.g., wild-land fires; also related to population migration), increase in hazards, etc.

- Resource Supply: Such as water (i.e., quality, quantity, availability, access, and provision) acre/feet of water supply in reservoirs, food, energy (production; use; consumption patterns; different sources), land resources, food security /agriculture, coastal storms, ecosystem services, etc.

Major categories of CitSci applications in pre, during and post stages of natural disaster management are summarized in Figure 3. Mainly hazards are natural processes that have destructive potential. If a natural hazard results in common deaths and loss of properties, it is considered as natural disaster. The duringdisaster applications are added to the Figure for relatively long duration time of a hazard event, such as flood, tsunami, drought, forest fire, etc.

$$
\begin{aligned}
& \stackrel{2 \text { Pre-disaster }}{ } \\
& \rightarrow \text { Suitable site selection } \\
& \rightarrow \text { Risk assessment } \\
& \rightarrow \text { Capacity building } \\
& \rightarrow \text { Early-warning system } \\
& \rightarrow \text { Planning }
\end{aligned}
$$

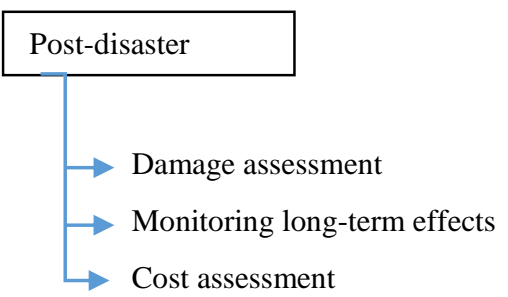

Aid provision

Figure 3. Potential contributions of CitSci in natural disaster management.

\subsection{CitSci Applications for Pre-Disaster Management}

At the pre-disaster stage, the contributions can be for the planning, production of susceptibility maps for landslide, flood, liquefaction (borehole data, engineering properties of soils), peak ground acceleration maps, lifeline and infrastructure site selection, and suitable engineering designs against these phenomena/hazards.

Environmental monitoring and protection is a key stage for disaster prevention and planning. Many environment-related CitSci projects are being implement in the last two decades, with an ongoing trend on the increase of such projects. Meteorological observations have volunteer contributions since the early start of systematic measurements of temperature, precipitation or extreme weather events (WMO 2001). Scott \& Barnett (2009) show a successful example of such a project in the 'Global Community Monitor', where communities deal with air pollution issues.

The susceptibility maps are produced for predicting the future hazards based on the past information and current data. As an initial stage, CitSci projects can be carried out to collect the local knowledge about the region and generate information based on those. Kocaman and Gokceoglu (2018) show the past cases where eye-witnesses contributions are analyzed for landslides and emphasize the possible contributions of CitSci for filling the gaps in landslide hazard assessment process. There are also recent large-scale projects which combine CitSci with landslide hazard assessments (Research Councils UK, 2018; Landslide EVO, 2018; USGS Landslide Hazards Program, 2018). Even though such projects exist also for other types of disasters in different countries, systematic approaches by governments are still largely missing.

\subsection{CitSci Applications for Post-Disaster Management}

At the post-disaster stage, the immediate contributions can be categorized as preparation and implementation of evacuation plans, rescue plans, mapping and attribution of transportation status, schools, hospitals, and other public buildings. In the long term, the monitoring of post-disaster effects, preparation of damage maps can be listed. Environmental monitoring projects play also an important role after disasters. 
Zook et al. (2010) have presented the use of volunteer geographical information for the Haitian Earthquake in 2010 and described the Haiti relief effort, especially with respect to webbased mapping services. They have used the Ushahidi platform, which translates to "testimony" in Swahili, was developed to map reports of violence in Kenya after the post-election violence in 2008 (https://www.ushahidi.com/). Another prominent application of CitSci in disaster management is Peta Jakarta Project (www.petajakarta.org, Holderness and Turpin, 2017), which has been developed as a close collaboration of university, local government and social media (Twitter). Although a few more applications can be listed here, they are all relatively new and further developments in the field are needed.

\section{ISSUES ON PUBLIC PARTICIPATION TO CITSCI PROJECTS}

There are several major issues regarding the citizen participation in disaster management. These are discussed briefly as follows:

i. Technical: Ubiquitous use of mobile devices as well as sensors getting cheaper allows citizen scientists to collect and disseminate data easily. Middleton et al (2014) devised a platform that would harness geospatial tweets to generate real-time crisis maps. The authors have emphasized on the importance of statistical analysis in order to minimize false alarms (i.e. reporting a disaster when there is none in reality). Open Geospatial Consortium (OGC) has also established a working group entitled "Emergency and Disaster Management". The various government agencies, research organizations, companies and non-governmental organizations having various roles in public safety, justice and disaster management must effectively communicate with each other. Consequently, the necessary interoperability standards must be ensured through relying on open OGC standards (OGC, 2017). As the communication links between various stakeholders grow, the management of large data sets, including its storage and analysis would be complex. Efficient querying of the collected data, designing optimal user interfaces for different levels of literacy or even illiteracy are important in the design of a disaster management system

ii. Data quality: Data quality is one of the most important aspects of CitSci research. As the data collection process is mostly handled by citizens, the quality of the data is questionable. There are several reasons for researchers to question the quality of CitSci data. To begin with, data are collected by many different citizens with different backgrounds, needs and motivation. In addition, these people might not necessarily use the same technological tools to collect data or even so they might perceive the measured phenomenon differently (Hollenstein and Purves, 2014; Montello 2003). Last, the lack of gatekeepers let the abuse of a VGI platform. Consequently, data quality is one of the most intriguing topics of CitSci. Recently, Senaratne et al (2017) reviewed the existing methods to assess the quality of VGI data. For different data types (image, text and map), they have gathered 30 methods for 17 quality indicators. Development of quality assessment techniques (statistical, logical, user checks, etc.) specific to the project, integrating quality control tasks as project design elements, provision of regular reports on the data quality and other project results and outputs are vital components of this process. iii. Management: Open data, government collaboration, language barriers. Increasing the political awareness especially in developing countries and the development of policies to increase the number and quality of such projects.

iv. Education: Preparation of training materials, on-site and online training of volunteer groups, defining the typology (different levels) of the volunteers and adapting the training per user group, overcoming the language barriers for training.

v. Legal: Communicating risks is a crucial component and doing it correctly requires responsibility. One of the important examples in this area is known as the L'Aquila Seven in which seven professionals were accused of having performed only a superficial analysis of seismic risk and providing false reassurances to the public ahead of the quake (Alexander, 2014). This false reassurance led to the death of 308 people on 6 April 2009 due to a 6.3 earthquake struck at L'Aquila. Another legal issue is regarding the languages of hazard maps. A comparative study between Japan and Spain highlight the similarities of practice and differences due to flood. For instance, nearly $10 \%$ of flood victims in Spain were foreign citizens and there was no obligation to make them available in foreign languages (Nakamura and Llasat, 2017). Risk management/insurance especially in the field work, ownership rights of the project data, outcomes and dissemination, responsibility issues in case of missing or false data are all situations in which legal guideance must be sought.

vi. Motivation: Sustaining the motivation of citizen scientists is an on-going research agenda (Coleman et al, 2009; Tang and Liu, 2016). There are many different ways in which a citizen scientist is motivated, but broadly there are two main types: intrinsic and extrinsic. There is a lack of research regarding the motivation of citizen scientists involved in a disaster management project. However, it is not difficult to imagine that most people would be willing to help their families or neighbours in a difficult time.

\section{The role of open government data}

Depending on the disaster type, governments and local authorities play the most significant role in disaster management at all stages. In order to solve different issues described until here, the policies, openness, and coordination activities of the governments are extremely important. The concept of open government data becomes crucial for successful disaster management.

The Open Definition Project (2018) developed by the Open Knowledge Foundation (2018), states that open means anyone can freely access, use, modify, and share for any purpose. Thus, open data and content can be freely used, modified, and shared by anyone for any purpose (Open Definition Project, 2018). According to Open Knowledge Foundation (2018), the key features of openness are:

- Availability and access: the data must be available as a whole and at no more than a reasonable reproduction cost, preferably by downloading over the internet. The data must also be available in a convenient and modifiable form.

- Reuse and redistribution: the data must be provided under terms that permit reuse and redistribution including the intermixing with other datasets. The data must be machinereadable. 
- Universal participation: everyone must be able to use, reuse and redistribute - there should be no discrimination against fields of endeavor or against persons or groups. For example, 'non-commercial' restrictions that would prevent 'commercial' use, or restrictions of use for certain purposes (e.g. only in education), are not allowed.

Governments spend billions on acquisition of different data, which in nature should be open to the public. According to Open Data Institute (2018), open government data is:

- data produced or commissioned by government

- that anyone can freely access, use, modify, and share for any purpose

In July 2013, G8 leaders signed the G8 Open Data Charter, which outlined a set of five core open data principles. The revised form came out in 2015 resulting the following 6 principles (Open Data Charter, 2018):

1. Open by Default;

2. Timely and Comprehensive;

3. Accessible and Useable;

4. Comparable and Interoperable;

5. For Improved Governance and Citizen Engagement; and

6. For Inclusive Development and Innovation

\section{CONCLUSIONS}

The gaps in disaster-related research and potential contributions of citizen scientists to these fields should be identified by researchers and published periodically on CitSci platforms. The ten principles of $\mathrm{CitSci}$ introduced by European $\mathrm{CitSci}$ Association (ECSA, 2015) is a Beginner's Guide of such projects, which definitely will be extended with further developments and increasing knowledge.

In the present study, a summary describing the potential use of $\mathrm{CitSci}$ in disaster management is introduced. For this purpose, the disaster management is classified into three phases namely pre-, during and post-disaster. The possible roles of CitSci in these phases are described. At present, it is evident that the involvement of CitSci in disaster management efforts are still limited. However, when considering the possible roles of citizens in disaster management, an increasing trend on CitSci contribution cannot be overlooked.

Increase in the number of natural hazards is expected and it is impossible to prevent these hazards or to decrease the number of the hazards. In order to minimize the loss of lives, all stakeholders should consider effective ways in which to utilize $\mathrm{CitSci}$. The better the use of local knowledge in a disaster struck area, the better the aid is delivered. As described herein, if the CitSci contribution to natural disaster management is provided sufficiently, the quality and success of disaster management efforts will increase. Especially, CitSci contribution to the during disaster phase has a crucial importance because the data collection during a disaster is extremely difficult or almost impossible by conventional methods. Consequently, CitSci is a useful tool but the roles of different stakeholders should be taken into consideration in natural disaster management efforts as described in the present study.

\section{REFERENCES}

Alexander, D.E., 2014. Communicating earthquake risk to the public: the trial of the "L'Aquila Seven". Nat Hazards 72, 11591173. https://doi.org/10.1007/s11069-014-1062-2

Bonney, R., Ballard, H., Jordan, H., McCallie, E., Phillips, T., Shirk, J. and Wilderman, C. (2009). Public Participation in Scientific Research: Defining the Field and Assessing Its Potential for Informal Science Education. A CAISE Inquiry Group Report, Center for Advancement of Informal Science Education (CAISE), Washington, DC, Tech. Rep.

Coleman, D., Georgiadou, Y., Labonte, J., (2009), Volunteered Geographic Information: the nature and motivation of produsers. Int. J. Spat. Data Infrastruct. Res. 4, 332-358

Cooper, C. B., Dickinson, J., Phillips, T., and Bonney, R. (2007). CitSci as a Tool for Conservation in Residential Ecosystems. Ecology and Society, 12(2), 11. URL:

http://www.ecologyandsociety.org/vol12/iss2/art11/

Cutter S.L., Ismail-Zadeh, A., Alcantara-Ayala, I., Altan, O., Baker, D.N., Briceño, S., Gupta, H., Holloway, A., Johnston, D., McBean G.A., Ogawa, Y., Paton, D., Porio, E., Silbereisen, R.K., Takeuchi, K., Valsecchi, G.B., Vogel, C. And Wu, G., 2015. Global risks: Pool knowledge to stem losses from disasters Nature 522: 277-279. doi:10.1038/522277a

ECSA, 2015. Ten principles of CitSci. https://ecsa.citizenscience.net/sites/default/files/ecsa_ten_principles_of_citizen_sci ence.pdf (accessed on 15.02.2018)

Goodchild, M. (2007). Citizens as sensors: the world of volunteered geography. GeoJournal, 69, 211-21.

Haklay, M., 2013. CitSci and volunteered geographic information: Overview and typology of participation. In Crowdsourcing geographic knowledge (pp. 105-122). Springer Netherlands. doi:10.1007/978-94-007-4587-2_7

Haklay, M., Francis, L., and Whitaker, C. (2008). Citizens tackle noise pollution. GIS professional, August issue

Haworth, B., Bruce, E., 2015. A Review of Volunteered Geographic Information for Disaster Management. Geography Compass 9, 237-250. https://doi.org/10.1111/gec3.12213

Holderness, T., Turpin, E., 2017. PetaJakarta.org: Assessing the Role of Social Media for Civic Co-Management During Monsoon Flooding in Jakarta, Indonesia. White Paper. SMART Infrastructure Facility, University of Wollongong ISBN: 978-174128-249-8)

Hollenstein, L. and Purves, R., 2014. Exploring place through user-generated content: using Flickr tags to describe city cores. Journal of Spatial Information Science, 1, 21-48

Kocaman, S., Gokceoglu, C., 2018. Possible Contributions of CitSci for Landside Hazard Assessment. Proceedings of Geoinformation for Disaster Management (GI4DM) 2018, March 19-22, Istanbul.

Landslide EVO, 2018. http://www.iiasa.ac.at/web/home/ research/researchPrograms/RISK/Landslide-EVO.html (accessed on 10.02.2018). 
Maisonneuve, N., Stevens, M., and Ochab, B., 2010. Participatory noise pollution monitoring using mobile phones. Information Polity, 15(1-2), 51-71

Middleton, S. E., Middleton, L., and Modafferi, S., 2014. RealTime Crisis Mapping of Natural Disasters Using Social Media. in IEEE Intelligent Systems, vol. 29, no. 2, pp. 9-17, Mar.-Apr. 2014.

Montello, D.R., et al., 2003. Where's downtown? Behavioral methods for determining referents of vague spatial queries. Spatial Cognition \& Computation, 3 (2-3), 185-204. doi: $10.1080 /$

13875868.2003.9683761

Munich RE, 2017. Natural Disasters: The Year in Figures. https://www.munichre.com/topics-online/en/2017/topicsgeo/overview-natural-catastrophe-2016. (accessed on 15.02.2018)

Nakamura, I., Llasat, M.C., 2017. Policy and systems of flood risk management: a comparative study between Japan and Spain. Nat Hazards 87, 919-943. https://doi.org/10.1007/s11069-0172802-x

National Climate Assessment Report, 2011. Climate Change Impacts and Responses. NCA Report Series Vol. 5c, April 2829, Washington D.C., U.S.A.

OGC, 2017. http://www.opengeospatial.org/projects/groups/ edmdwg

Research Councils UK, 2018. http://gtr.rcuk.ac.uk/ projects? $\mathrm{ref}=\mathrm{NE} \% 2 \mathrm{FP} 000452 \% 2 \mathrm{~F} 1$. (accessed on 10.02.2018).

See, L., Mooney, P., Foody, G., Bastin, L., Comber, A., Estima, J., Fritz, S., Kerle, N., Jiang, B., Laakso, M., Liu, H.-Y., Milčinski, G., Nikšič, M., Painho, M., Pődör, A., OlteanuRaimond, A.-M., Rutzinger, M., 2016. Crowdsourcing, CitSci or Volunteered Geographic Information? The Current State of Crowdsourced Geographic Information. ISPRS Int. J. Geo-Inf., 5,55 .

UN Sustainable Development Goals, 2018. http://www.un.org/sustainabledevelopment/sustainabledevelopment-goals/ (accessed on 15.02.2018)

USGS Landslide Hazards Program, 2018. https://landslides.usgs.gov/ (accessed on 10.02.2018).

Open Data Charter, 2018. https://opendatacharter.net/ (accessed on 12.02.2018)

Open Definition Project, 2018. http://opendefinition.org/ (accessed on 12.02.2018).

Open Knowledge Foundation, 2018. https://okfn.org/ (accessed on 12.02.2018).

Senaratne, H., Mobasheri, A., Ali, A.L., Capineri, C., Haklay, M., 2017. A review of volunteered geographic information quality assessment methods, International Journal of Geographical Information Science, 31:1, 139-167, DOI: $10.1080 / 13658816.2016 .1189556$
Scott, D., and Barnett, C., 2009. Something in the air: civic science and contentious environmental politics in post-apartheid South Africa. Geoforum, 40(3), 373-382

Silvertown, J., 2009. A new dawn for CitSci. Trends in Ecology \& Evolution 24, 467-471.

Tang, Z., Liu, T., 2016. Evaluating Internet- based public participation GIS (PPGIS) and volunteered geographic information (VGI), Environmental Planning and Management. Journal, 59, 1073-1090.

Wiggins, A., and Crowston, K., 2011. From conservation to Crowdsourcing: A typology of CitSci, in Proceedings of the Forty-fourth Hawaii International Conference on System Science (HICSS-44), Koloa, HI, 1/2011

Wilderman, C.C., 2007. Models of community science: design lessons from the field, in C. McEver, R. Bonney, J. Dickinson, S. Kelling, K. Rosenberg, and J. L. Shirk, (Eds.) CitSci Toolkit Conference, Cornell Laboratory of Ornithology, Ithaca, NY.

World Meteorological Organisation, 2001. Volunteers for Weather, Climate and Water. Geneva, Switzerland, WMO No. 919

Zook, M., Graham, M., Shelton, T., and Gorman, S., 2010. Volunteered Geographic Information and Crowdsourcing Disaster Relief: A Case Study of the Haitian Earthquake. World Medical \& Health Policy: 2(2) Art. 2 DOI: 10.2202/19484682.1069 